\title{
Phosphorus Adsorption a Foamed Waste Glass
}

\author{
Harada Hiroyuki*1 ${ }^{\text {, Asmak A Filiana }}{ }^{1}$, Nishikawa Hanami ${ }^{1}$ and Tomoyuki Miyamoto ${ }^{2}$ \\ ${ }^{1}$ Purefectural University of Hitohima University, Japan
}

${ }^{2}$ COCCO LTD, Japan

*Corresponding author: Harada Hiroyuki, Purefectural University of Hitohima University, Japan, Email: ho-harada@pu-hiroshima.ac.jp

Submission: 海 February 25, 2018; Published: 毕 May 11, 2018

\section{Introduction}

Phosphorus ores will be exhausted in about 80 years [1]. The development of phosphorus-recycling systems would help to counteract phosphorus depletion. Foamed glass materials have a porous structure that incorporates a large number of voids and are conventionally used as civil engineering materials or aggregates for construction [2]. Since calcium carbonate is used as the foaming agent, and it can be used as an adsorbent for phosphorus. In this study, we investigated phosphorus removal from environmental water using foamed glass.

\section{Materials and Experimental Methods}

\section{Batch experiment}

The samples of foamed glass tested in this study were collected from a production site in Kure City, Hiroshima, Japan (Figure 1). A model environmental water sample with a phosphate concentration of $1 \mathrm{mM}$ was pre pared and its initial $\mathrm{pH}$ was adjusted from 2 to 7 with $0.1 \mathrm{M}$ sulfuric acid and sodium hydroxide solution. The solution ( $40 \mathrm{~mL}$ ) and the adsorbent (1g), i.e. a liquid/solid ratio of $20 \mathrm{~mL} / \mathrm{g}$, were placed in a $50 \mathrm{~mL}$ centrifuge tube in a small rotating agitator in a thermostatic chamber at $30^{\circ} \mathrm{C}$. Agitation was performed at $40 \mathrm{rpm}$ for $24 \mathrm{~h}$. After separation, filtration was performed with 5 type C filter paper and the phosphate in the filtrate was determined by molybdenum blue spectrophotometers.

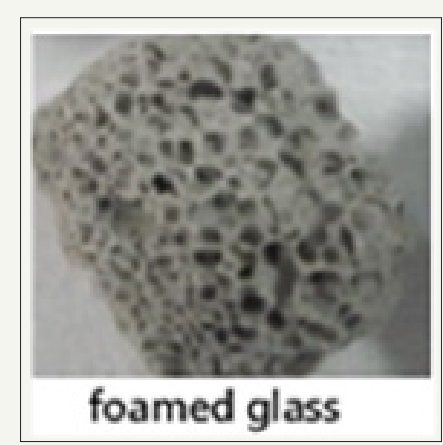

Figure1: Formed glass.

\section{Continuous treatment experiment}

Foamed glass was into a pressure-resistant glass column of diameter $1 \mathrm{~cm}$ and length $30 \mathrm{~cm}$, so that the glass was filled to $15 \mathrm{~cm}$ from the top of the column. Raw water was supplied from the bottom to obtain treated water. A raw water sample with suspended solid concentration $18 \mathrm{mg} / \mathrm{L}, \mathrm{pH} 4.2$, phosphate concentration $2.5 \mathrm{mg} / \mathrm{L}$ and nitrate nitrogen concentration $1.0 \mathrm{mg} / \mathrm{L}$ was obtained from a wastewater treatment facility at the Prefectural University of Hiroshima and used for this experiment.

\section{Result and Discussion}

Figure 2 shows the effect of the equilibrium $\mathrm{pH}$ on the adsorption capacity. Initial $\mathrm{pH}$ adjusted $\mathrm{pH}$ 2-7 and they are shifted to 8.4-10.8 in equilibrium condition. Adsorption capacity shows $1.9 \mathrm{mg} / \mathrm{g} \sim 3.3 \mathrm{mg} / \mathrm{g}$. The saturated adsorption amount was estimated $3.3 \mathrm{mg} / \mathrm{g}$. The amount of material adsorbed per gram of adsorbent (q) was calculated from the difference between the concentrations before and after treatment,

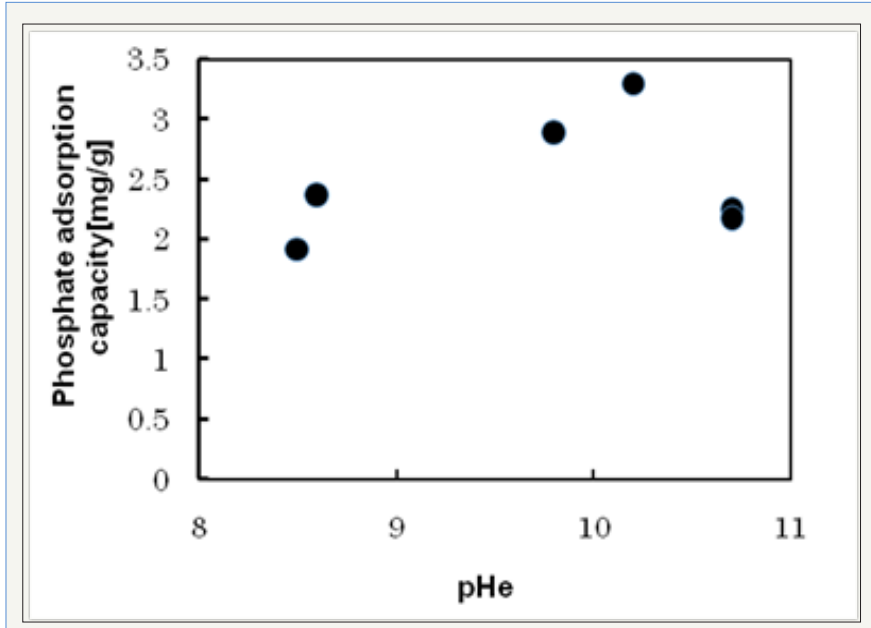

Figure2: The effect of the equilibrium $\mathrm{pH}$ on the adsorption capacity. 
the treatment volume and the equilibrium concentration (Ce). The values of $\ln (q)$ and $\ln (\mathrm{Ce})$ can be give the Fruindrich relationship equation based on Figure 2.

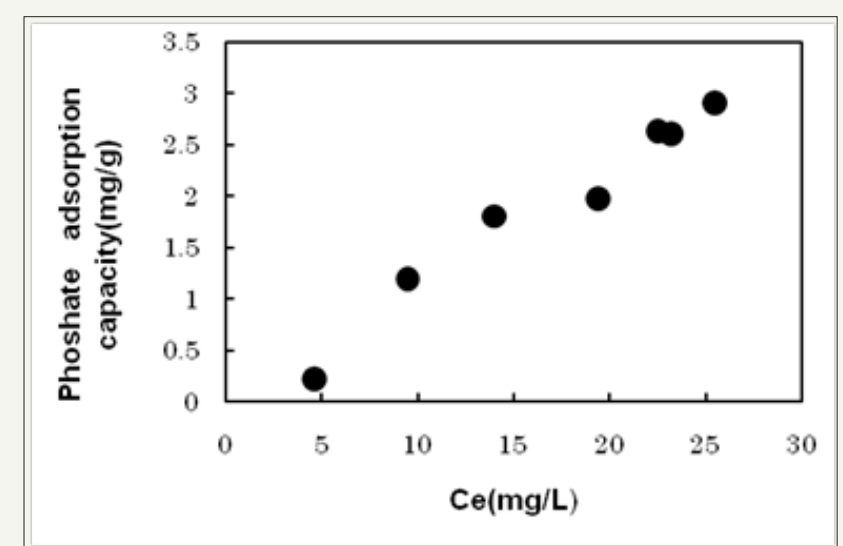

Figure 3: Isothermal adsorption experiment $\left(30^{\circ} \mathrm{C}, \mathrm{pHi} 4\right)$.

$$
\begin{aligned}
& \mathrm{Q}=0.032 \mathrm{Ce}^{1.43} \\
& \mathrm{R}^{2}=0.93
\end{aligned}
$$

Figure 3 Batch experiment the concentration of treated water gradually decreased from 1.5 to $0.2 \mathrm{mg} / \mathrm{L}$, after that became constant at about $0.5 \mathrm{mg} / \mathrm{L}$. No clear breakthrough was observed.
This gradually decreases in concentration due to diffusion into the inside. After that, it is thought that the diffusion adsorption to the inside decreased and became flat (Figure 4).

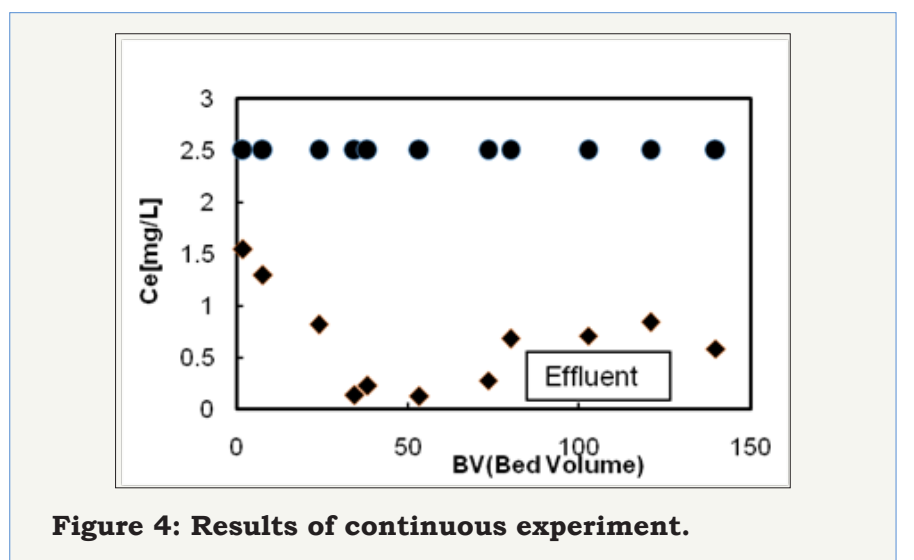

\section{Acknowledgement}

This research was funded by the Ministry of Education, Culture, Sports, Science, and Technology, Japan (Grant no. 15K00605).

\section{References}

1. Abelson PH (2015) Science. p. 283.

2. Kazmina OV, Tokarev AY, Vereshchagin (2016) Resource-efficient technologies. 2: 23-29. (c) (i) Creative Commons Attribution 4.0 International License

For possible submissions Click Here

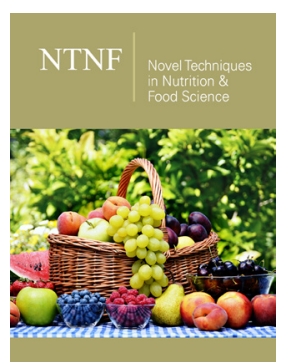

Novel Techniques in Nutrition and Food Science

\section{Benefits of Publishing with us}

- High-level peer review and editorial services

- Freely accessible online immediately upon publication

- Authors retain the copyright to their work

- Licensing it under a Creative Commons license

- Visibility through different online platforms 